Gut, 1988, 29, 284-290

\title{
Acid stimulated alkaline secretion in the rabbit duodenum is passive and correlates with mucosal damage
}

\author{
P VATTAY, W FEIL, S KLIMESCH, E WENZL, M STARLINGER, \\ AND R SCHIESSEL \\ From the University Clinic of Surgery I, Vienna General Hospital, Vienna, Austria and the First Surgical \\ Department, University School of Medicine, Szeged, Hungary
}

SUMMARY Low luminal acid concentrations stimulate alkaline secretion (AS) by the duodenal mucosa. We investigated acid stimulated alkaline secretion by proximal rabbit duodenal mucosa in an Ussing-chamber under different luminal acid concentrations and its relation to mucosal damage. Luminal alkalinisation and potential difference (PD) were measured and mucosal damage was investigated histologically. Luminal acid caused an increase of alkaline secretion over baseline $\left(0.95 \pm 0 \cdot 19 \mu \mathrm{Eq} / \mathrm{cm}^{2} / 10 \mathrm{~min} ; \mathrm{n=55}\right): 0 \cdot 1 \mathrm{mmol}: 7 \%, 1 \mathrm{mmol} / \mathrm{l}: 17 \%, 5 \mathrm{mmol} / \mathrm{l}: 22 \%, 10 \mathrm{mmol} / \mathrm{l}:$ 33\%, $20 \mathrm{mmol} / \mathrm{l}: 34 \%, 50 \mathrm{mmol}: 39 \%, 100 \mathrm{mmol} / \mathrm{l}: 27 \%$. At acid concentrations of $10 \mathrm{mmol} / \mathrm{l}$ and above the PD fell from $2 \cdot 0 \pm 1 \cdot 0 \mathrm{mV}$ to zero. Histology showed $\left[\mathrm{H}^{+}\right]$-dependent mucosal damage ranging from villus tip lesions to deep mucosal injury. Stimulation of alkaline secretion was not specific for acid. Ethanol (14\%) stimulated alkaline secretion by $26 \%$, and $28 \%$ ethanol by $40 \%$ over baseline. Ouabain and/or anoxia sensitive (active) alkaline secretion constituted $80 \%$ and $100 \%$ respectively of basal alkaline secretion. After exposure to various luminal acid concentrations passive diffusion (sensitive only to removal of nutrient $\mathrm{HCO}_{3}-$ ) was solely responsible for the rise in alkaline secretion. Only after $14 \%$ ethanol a small rise in ouabain and/or anoxia sensitive $\mathrm{HCO}_{3}-$ transport was observed. Under the conditions of this study stimulation of duodenal alkaline secretion is not specific for luminal acid, but occurs also with luminal ethanol; both agents stimulate alkaline secretion depending on their concentration. In this model passive diffusion of $\mathrm{HCO}_{3}-$ associated with increasing mucosal damage is the major component of the rise in alkaline secretion.

The mechanisms which enable the duodenal mucosa to resist luminal acid are not fully understood. Several studies have shown that the duodenal mucosa transports bicarbonate into the lumen..$^{1-3}$ It has been proposed that this is important for disposal of luminal acid and thus for mucosal protection. ${ }^{+}$The alkaline secretion can be stimulated by low concentrations of luminal acid. This has been shown in various species in vivo and in vitro, and it was presumed to be a physiological mechanism. ${ }^{5-12}$

The aim of the present study was to investigate the

Address for correspondence: Prof Dr Rudolf Schiessel, University Clinic of Surgery I, Vienna General Hospital, A-1090 Vienna, Austria.

Received for publication 24 August 1987. influence of different acid loads on $\mathrm{HCO}_{3}-$ transport by the duodenal mucosa in vitro to gain further insight about the role of active and passive transport in acid stimulated alkaline secretion and the association of alkaline secretion with mucosal damage.

\section{Methods}

ANIMALS

A segment of the proximal duodenum (approximately $3 \mathrm{~cm}$ from the pylorus) of anaesthetised female New Zealand white rabbits (mean weight: $3 \mathrm{~kg}$, Ivanovas, Kissleg, FRG) was excised. The external muscle layer was separated immediately by blunt dissection in an unbuffered, aerated solution at 
room temperature and mounted as a membrane horizontally between the two halves of an in vitro chamber as originally described by Sjöstrand..$^{13}$ The area of the exposed mucosal surface was $2 \mathrm{~cm}^{2}$. The volume of the chamber was $6 \mathrm{ml}$. The nutrient solution was buffered to $\mathrm{pH} 7.4$ with $25 \mathrm{mmol} / \mathrm{l}$ $\mathrm{HCO}_{3}$ - and contained in mmol/l: $122 \mathrm{NaCl}, 5 \mathrm{KCl}, 2$ $\mathrm{CaCl}, 1 \cdot 3 \mathrm{MgSO}_{4}$, and 20 glucose. This solution was gassed with $95 \% \mathrm{O}_{2} / 5 \% \mathrm{CO}_{2}$. No buffers were used on the luminal side where a $\mathrm{NaCl}(154 \mathrm{mmol} / \mathrm{l})$ solution was gassed with $100 \% \mathrm{O}_{2}$ (prewashed in $\mathrm{KOH}, 4 \mathrm{M})$. The temperature in the bath was maintained at $37^{\circ} \mathrm{C}$ by means of a water jacket. Luminal alkalinization was measured at $\mathrm{pH}=7 \cdot 4$. The luminal $\mathrm{pH}$ was kept constant by infusion of 100 $\mathrm{mmol} / \mathrm{l} \mathrm{HCl}$ under automatic control from a $\mathrm{pH}$-statsystem (Radiometer, Copenhagen, Denmark). After recording of steady state alkaline secretion for 30 minutes, the luminal solution was changed to one containing different concentrations of $\mathrm{HCl}$ with $\mathrm{NaCl}$ added to achieve a total ionic strenth of 308 $\mathrm{mOsmol} / \mathrm{l}$. In experiments designed to examine the effects of ethanol, the luminal solution was changed to one containing $14 \%$ or $28 \%$ ethanol in addition to $\mathrm{NaCl}, 154 \mathrm{mmol} / \mathrm{l}$. After 10 minutes of exposure the acid or ethanol containing solution was washed out by $15-20$ changes of the luminal bathing fluid with $\mathrm{NaCl}, 154 \mathrm{mmol} / \mathrm{l}$. Measurement of alkaline secre-

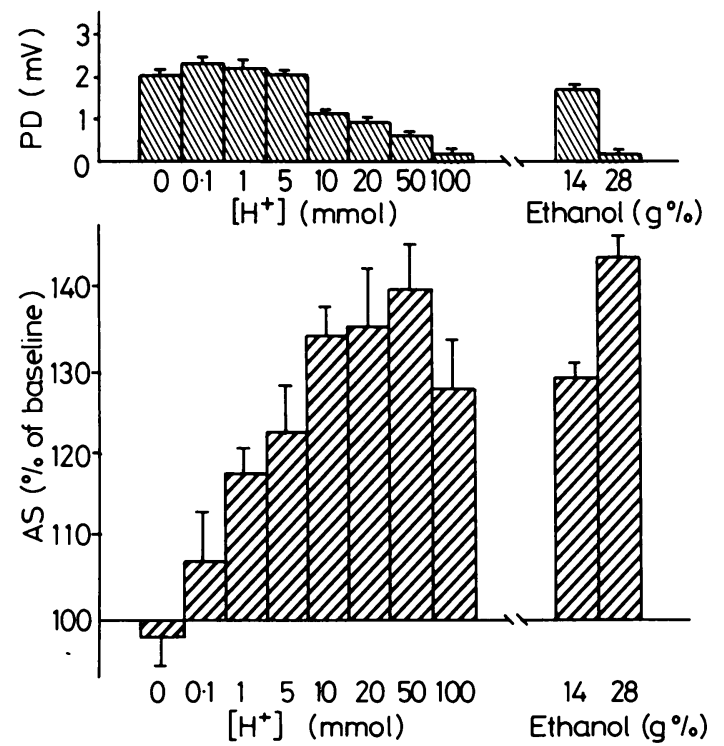

Fig. 1 Alkaline secretion (AS) and potential difference (PD) after exposure to different concentrations of acid (control: $n=8,0.1 \mathrm{mmol}: n=4,1 \mathrm{mmol}: n=6,5 \mathrm{mmol}: n=6$, $10 \mathrm{mmol}: \mathrm{n}=6,20 \mathrm{mmol}: \mathrm{n}=7,50 \mathrm{mmol}: \mathrm{n}=8,100 \mathrm{mmol}$ : $n=10)$ and ethanol $(14 \%: n=6,28 \%: n=6)$. Values are means (SE). tion was restarted when the luminal $\mathrm{pH}$ again reached $\mathrm{pH}=7 \cdot 4$. The time required to reach this $\mathrm{pH}$ spontaneously was $10-20$ minutes after exposure to $1 \mathrm{mM} \mathrm{HCl}$, but $60-80$ minutes were required after 10 $\mathrm{mmol} / \mathrm{l} \mathrm{HCl}$ and $100-140$ minutes after $50 \mathrm{mmol} / \mathrm{l}$ $\mathrm{HCl}$. After reappearance of luminal alkalinisation at $\mathrm{pH}=7.4$ and irrespective of the time interval to the injury, measurable alkaline secretion rose quickly within 30-40 minutes to reach a steady state that was maintained for the remainder of the experiment. Therefore the means of the 3 highest consecutive steady state values of alkaline secretion were used for subsequent statistical analysis and presentation of the data. The PD was measured every 10 minutes between 2 agar bridges $(\mathrm{KCl}, 3 \mathrm{M})$ connected through two calomel reference electrodes (K 4040, Radiometer, Copenhagen, Denmark) to a voltmeter (pHM 82, Radiometer).

In order to characterise components of active transport and to differentiate between active and passive transport of $\mathrm{HCO}_{3}-$, ouabain (Sigma Chemie GmbH, Munich, FRG) was added in some experiments to the nutrient solution to a final concentration of $10^{-3} \mathrm{M}$, and/or all metabolism-dependent transport was inhibited by anoxia (gassing change to $95 \% \mathrm{~N}_{2} / 5 \% \mathrm{CO}_{2}$ on the nutrient side and $100 \% \mathrm{~N}_{2}$ on the luminal side). To inhibit the passive component of bicarbonate secretion after oubain and/or anoxia treatment the nutrient solution was changed for a bicarbonate free one. In this solution $\mathrm{HCO}_{3}-$ was replaced by $\mathrm{H}_{2} \mathrm{PO}_{4}-$ or TRIS and gassed with $100 \%$ $\mathrm{O}_{2}$. At the end of each experiment the tissue was carefully removed from the chamber, pinned to a corkplate and fixed with $5 \%$ formalin at $\mathrm{pH}=7$. Three sections taken $3 \mathrm{~mm}$ apart were then embedded in paraffin. From these sections a total of at least six (two of each block) semithin $(2 \mu \mathrm{m})$ sections were cut and stained with haematoxylin and eosin for light microscopy. The morphological evaluation was carried out by an unbiased observer, who was unaware of the experimental conditions.

Mucosal damage was evaluated both qualitatively and quantitatively. In order to estimate the depth of damage we used the following scoring system: stage 0 : no damage visible in light microscopy; stage 1 : villus tip lesion; stage 2 : damage confined to the upper half of the villi; stage 3:50 up to $80 \%$ of villus height affected by necrosis; stage 4 : lesion as far as the base of the crypt; stage 5 : full thickness necrosis.

The extent of epithelial damage was assessed by counting all villi from the six different sections and by calculating the percentage of damaged villi for each duodenal sheet. The 'damage index' was calculated using the formula:

$$
\text { DI }(\text { damage index })=\text { stage }(0-5) \times \text { extent }(\%)
$$




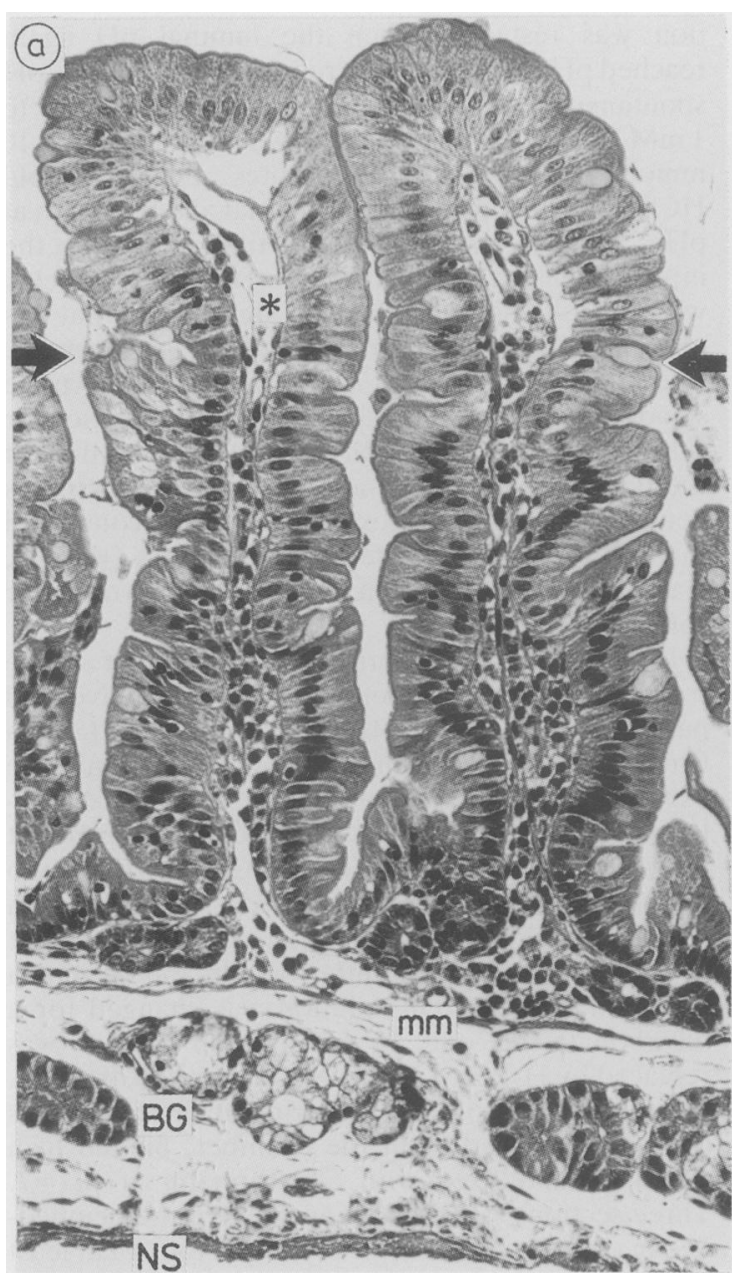

Fig. $2 \mathrm{a}$

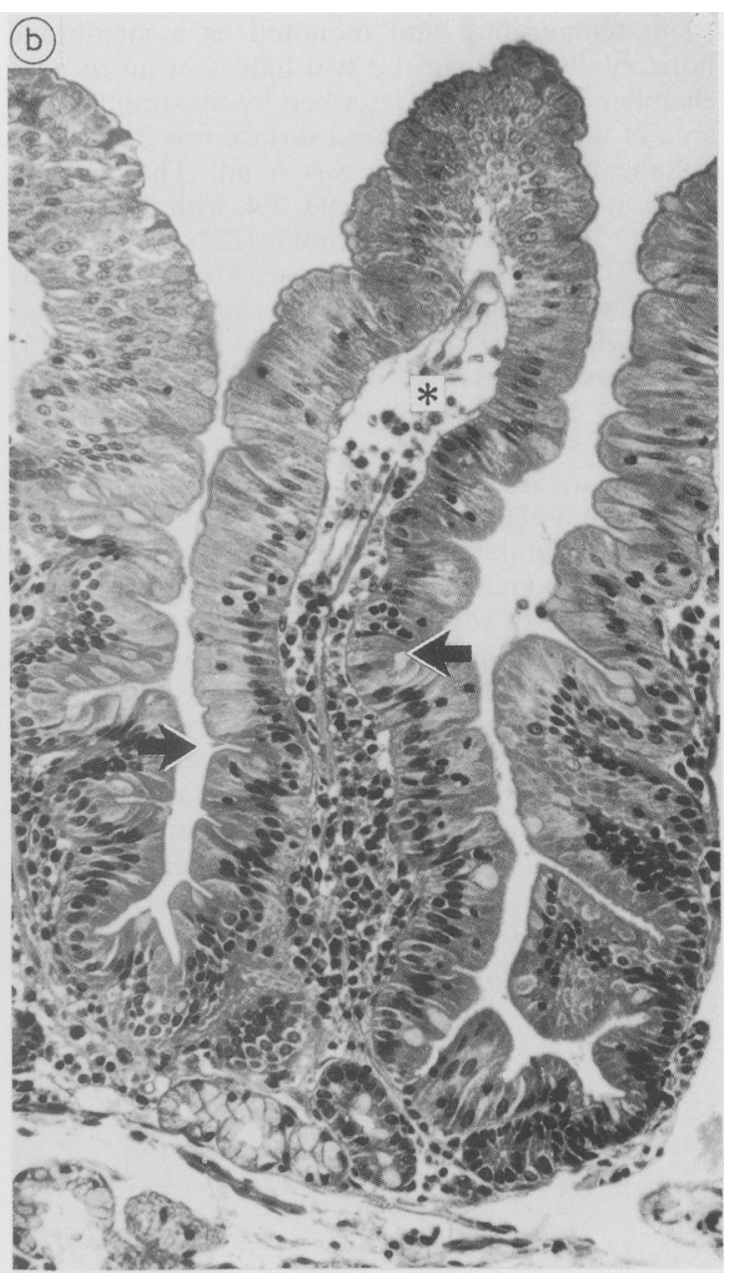

Fig. 2b

Fig. 2 (a) Lesion confined to the upper part of the villus (stage 2) caused by 5 mmol HCl; note: propria tissue $\left(^{*}\right.$ ) remains intact. BG: Brunner's glands. mm: muscularis mucosae. $n$ s: nutrient side. Demarcation border marked by $\rightarrow \leftarrow(H \& E)$. (b) $50 \%$ of villus height damaged after $10 \mathrm{mmol} \mathrm{HCl}$ (stage 3); note: necrotic propria tissue marked by ${ }^{*}$. Demarcation border marked by $\rightarrow \leftarrow(H \& E)$. (c) $80 \%$ of villus height affected by necrosis after 20 mmol $\mathrm{HCl}$ (stage 3); note: the crypt cells remain intact $\left(^{*}\right)$. Demarcation border marked by $\rightarrow \leftarrow(H \& E)$. (d) Lesion as far as the base of the crypts (stage 4) caused by 50 mmol HCl. Necrotic crypt cells marked by* $(H \& E)$.

STATISTICAI. ANALYSIS

Statistical analysis of the data was performed using the Mann-Whitney test and Kendall's Tau correlation coefficient for unpaired data. All values are given as means (SE).

\section{Results}

Under basal conditions the mucosa maintained a stable PD and secretory rate for at least six hours. Mean values of PD and alkaline secretion for 76 tissues were $1.96(0.41) \mathrm{mV}$ and $0.95(0.19) \mu \mathrm{Eq} / \mathrm{cm}^{2}$ $10 \mathrm{~min}$.

\section{EFFECT OF LUMINAL ACID}

In the first series of experiments the influence of different luminal acid concentrations on duodenal $\mathrm{HCO}_{3}$ - transport and PD were investigated $(\mathrm{n}=55)$. Luminal acid exposure was followed by an increase of alkaline secretion over baseline that was dependent in magnitude on the luminal acid concentration (Fig. 1). Higher concentrations of acid produced a 


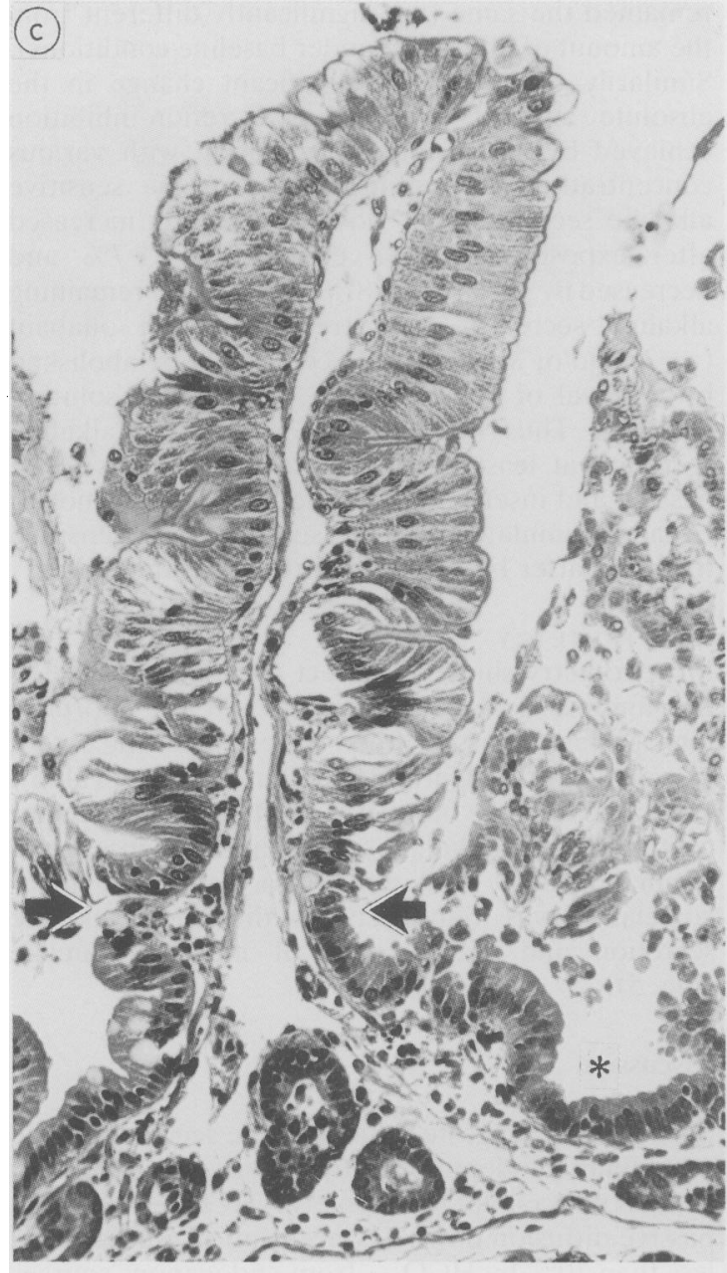

Fig. 2c

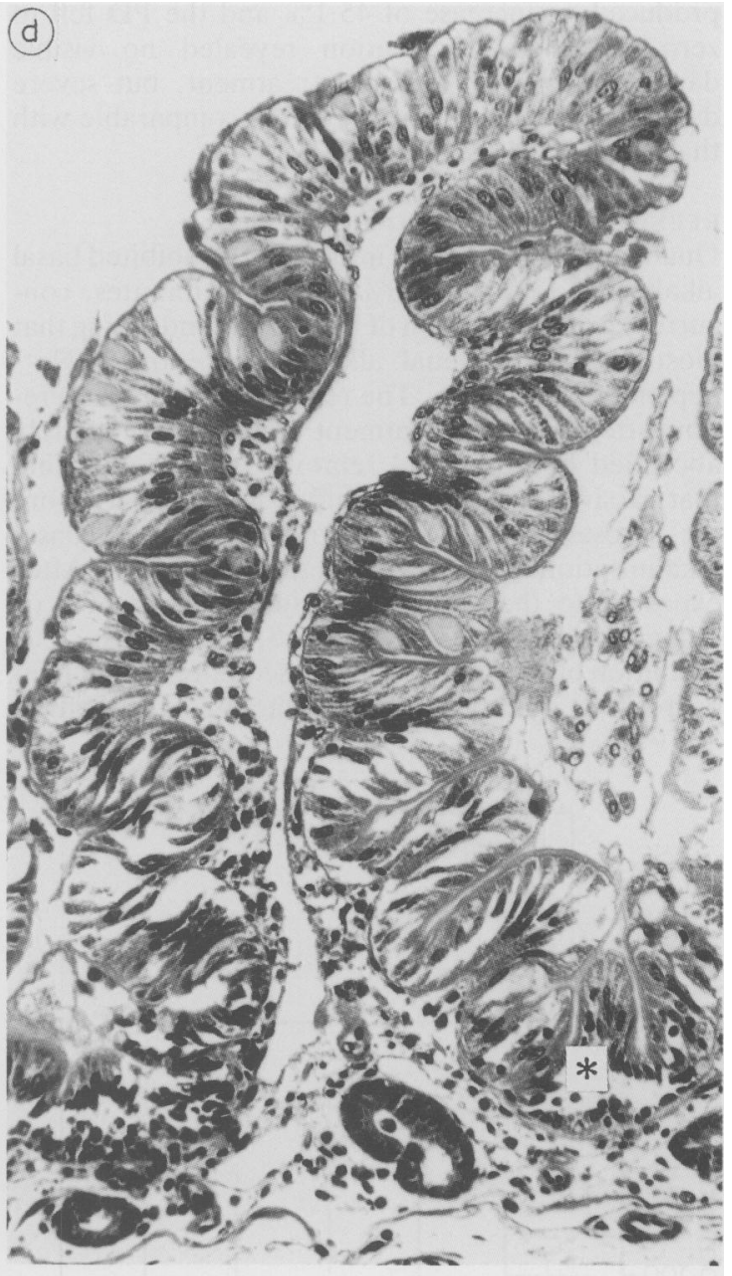

Fig. 2d stronger stimulation of alkaline secretion than low concentrations. Above $10 \mathrm{mmol} / \mathrm{l} \mathrm{HCl}$ there was no further stimulation of alkaline secretion. The PD, which remained stable during and after exposure to $0 \cdot 1 \mathrm{mmol} / \mathrm{l}, 1 \mathrm{mmol} / \mathrm{l}$, and $5 \mathrm{mmol} / \mathrm{l} \mathrm{HCl}$ was reduced after treatment with $10 \mathrm{mmol} / \mathrm{l} \mathrm{HCl}$ and higher acid concentrations. The suggestion, that this fall in PD indicated mucosal damage was supported by the results of the histological evaluation of the mucosae. Treatment with $0 \cdot 1 \mathrm{mmol} / \mathrm{l} \mathrm{HCl}$ caused no visible damage. The exposure to $1 \mathrm{mmol} / \mathrm{l} \mathrm{HCl}$ induced lesions of apical mucosal cells and occasionally tip necrosis of villi. $5 \mathrm{mmol} / \mathrm{l} \mathrm{HCl}$ caused mucosal damage confined to the upper parts of the villi, the propria tissue in the villus axis remained intact (Fig. $2 \mathrm{a})$. In contrast to this, mucosal damage caused by $10 \mathrm{mmol} / \mathrm{l} \mathrm{HCl}$ affected at least $50 \%$ of villus height in
$83.7(2 \cdot 7 \%$ ) of all villi (Fig. 2 b). Up to $80 \%$ of villus height were necrotic after luminal exposure to $20 \mathrm{mmol} / \mathrm{l} \mathrm{HCl}$ (Fig. 2c). Large defects in the epithelial continuity were noticeable and the stroma of the villi was exposed. Damage after treatment with $50 \mathrm{mmol} / \mathrm{l} \mathrm{HCl}$ was even more extensive with necrotic changes reaching down to the crypt basis (Fig. 2d). One hundred millimoles $\mathrm{HCl}$ caused full thickness necrosis of the tissue.

EFFECT OF ETHANOL

In order to investigate whether these stimulating properties on duodenal alkaline secretion were specific for luminal $\mathrm{HCl}$, a series of mucosae was exposed to ethanol. After treatment with $14 \%$ ethanol the alkaline secretion increased by $25.3 \%$ above baseline with no change in PD, $28 \%$ ethanol 
produced an increase of $45 \cdot 1 \%$ and the PD fell to zero. Histologic evaluation revealed no visible damage after $14 \%$ ethanol treatment, but severe damage after $28 \%$ luminal ethanol comparable with that seen after $10 \mathrm{mmol} / \mathrm{l} \mathrm{HCl}$.

\section{EFFECT OF OUABAIN AND ANOXIA}

Ouabain $\left(10^{-3} \mathrm{M}\right)$ on the nutrient side inhibited basal alkaline secretion by $80 \%$ within 90 minutes, concurrent with a reduction of PD to zero, indicating that most of the duodenal alkaline secretion is $\mathrm{Na}^{+}-$ dependent and active. The remaining alkaline secretion after ouabain treatment could be completely abolished by additional removal of $\mathrm{O}_{2}$, indicating that passive (paracellular) diffusion of $\mathrm{HCO}_{3}$ - from the serosal solution does not contribute to basal alkalinisation in the rabbit isolated duodenum. After exposure to the various concentrations of acid or ethanol as indicated in Figure 3, the relative (\%) inhibition of stimulated alkaline secretion by ouabain decreased, but the absolute amount of inhibition

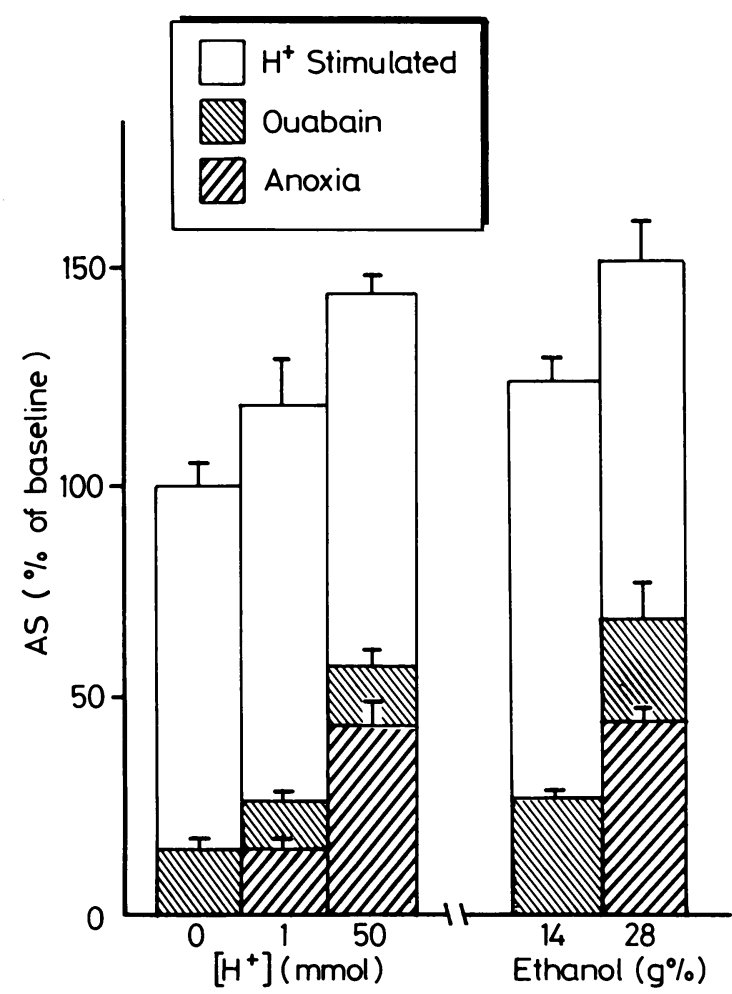

Fig. 3 Effect of ouabain and anoxia on acid stimulated alkaline secretion. Ouabain data represent values after 90 minutes of treatment. Anoxia data are values at 15 minutes after change of gassing. Values are means $(S E), n=6$ each group. remained the same (not significantly different from the amount of inhibition under baseline conditions). Similarily there was no significant change in the absolute amount of alkaline secretion-inhibition achieved by anoxia after stimulation with various concentrations of luminal $\mathrm{HCl}$. Anoxia sensitive alkaline secretion was, however, slightly increased after exposure to $14 \%$ ethanol by $21.7 \%$ and decreased by $9.9 \%$ after $28 \%$ ethanol. The remaining alkaline secretion after treatment with ouabain $(n=3)$ and/or anoxia $(n=6)$ could only be abolished by removal of $\mathrm{HCO}_{3}-$ from the nutrient solution (Fig. 4). Thus most of the increase of alkaline secretion at least after acid exposure seems to be passive and insensitive to either ouabain or anoxia. Ethanol-stimulated alkaline secretion was sensitive to anoxia after $14 \%$, but not after $28 \%$ ethanol.

\section{MORPHOMETRY}

Morphometry showed a direct correlation between the luminal acid concentration and the morphologic pattern of tissue injury in respect to the extent as well as to the depth of mucosal damage (Table). When the damage index was plotted against the per cent increase of alkaline secretion after exposure to luminal acid $(0 \cdot 1-50 \mathrm{mmol} / \mathrm{l})$ a significant linear correlation was found between the rise in alkaline secretion and the severity of mucosal damage (Fig. 5).

\section{Discussion}

Simson et $a l^{2}$ suggested that alkaline secretion in the amphibian duodenum in vitro consists to $50-60 \%$ of active transcellular transport of $\mathrm{HCO}_{3}-, 30-40 \%$ passive diffusion down a concentration gradient and less than $10 \%$ by $\mathrm{HCO}_{3}-$ from endogenous sources within the epithelium. Although comparable in vitro studies of mammalian duodenal mucosa are not available our results indicate, that passive shunt conductance of $\mathrm{HCO}_{3}-$ (serosa to mucosa) in the rabbit duodenum under control conditions is negligible. An equally low paracellular permeability has previously been found in lower parts of the rabbit small intestine - that is, ileum, where shunt conductance for $\mathrm{HCO}_{3}$ - was shown to be less than $10 \% .{ }^{14}$ As these, and our studies determined net luminal alkalinisation, however, we cannot exclude that secretion of $\mathrm{H}^{+}$or organic acids such as lactate or mucosal $\mathrm{CO}_{2}$ fluxes may have masked a small amount of passive $\mathrm{HCO}_{3}-$ secretion under the conditions of our experiments.

The stimulation of alkaline secretion by acid in the stomach and duodenum was first described by Heylings in the frog. ${ }^{56}$ This was later shown by others in the rat, "' dog, ${ }^{4}$ cat, ${ }^{7}$ rabbit ${ }^{12}$, and in man. ${ }^{11}$ This 


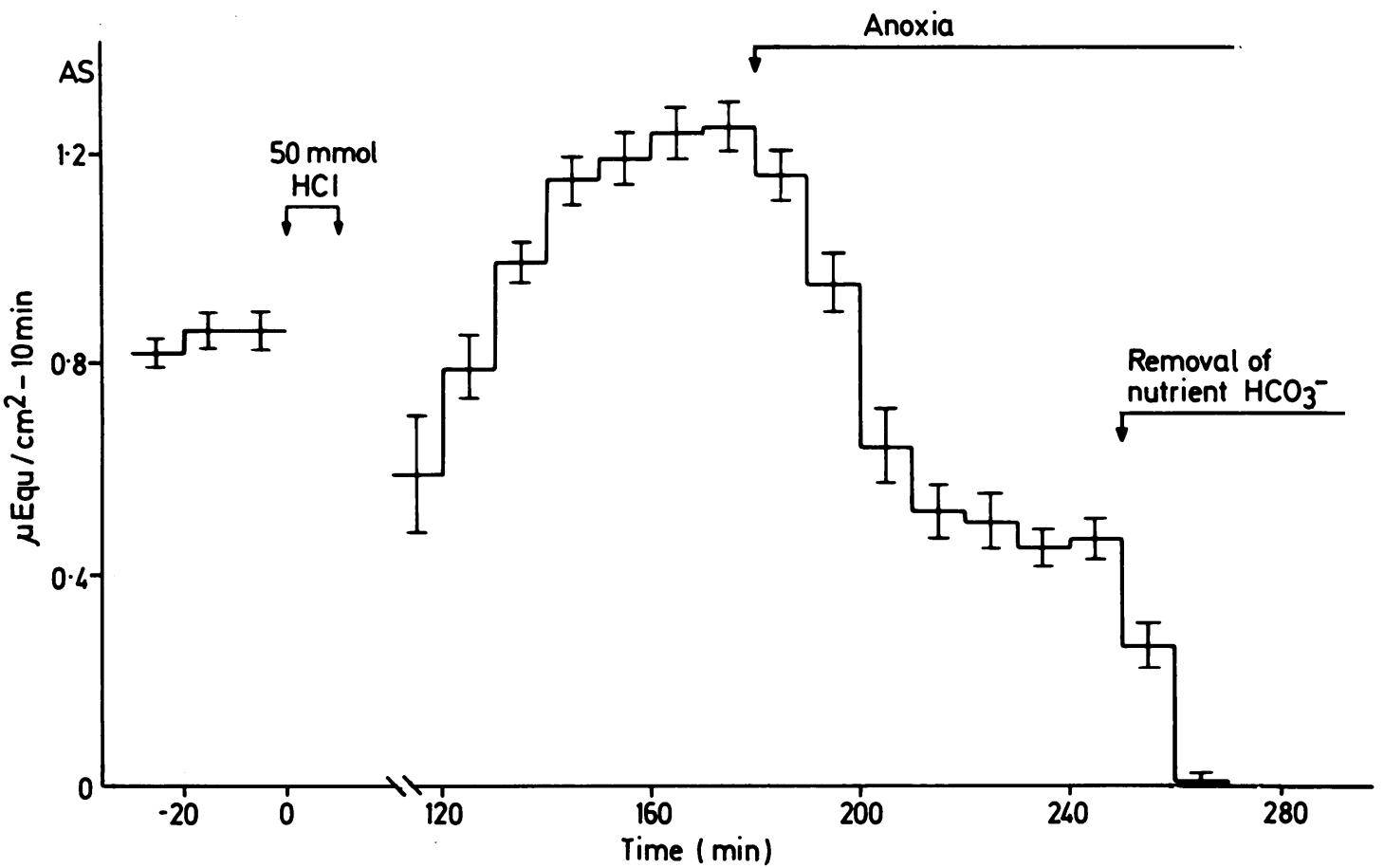

Fig. 4 Effect of removal of bicarbonate from the nutrient side on persisting alkaline secretion following anoxia. Values are means $(S E), n=6$.

implies that this is a physiological mechanism mediated by prostglandins enabling the duodenal mucosa to withstand luminal acid. Our experiments have clearly shown that in the rabbit the rise of alkaline secretion in response to luminal acid correlates with the mucosal damage produced by $\mathrm{HCl}$. It should be noted, however, that the rabbit is a continuous feeder and basal alkaline secretion in vivo is rather high, probably because of a continuous endgenous drive by prostaglandins as suggested by Flemström and Garner. ${ }^{1}$ This high basal alkaline secretion is refractory to further stimulation by exogenous prostaglandins. Therefore this particular

Table Mucosal damage after exposure to luminal acid

\begin{tabular}{ccclc}
\hline $\begin{array}{c}\text { mmol HCl } \\
\text { (for 10 min) }\end{array}$ & $n$ & $\%$ damaged villi & Stage & Damage index \\
\hline $0 \cdot 1$ & 6 & 0 & 0 & 0 \\
1 & 6 & $5 \cdot 93(1 \cdot 04)$ & 1 & $5 \cdot 93$ \\
5 & 6 & $83 \cdot 67(2 \cdot 7)$ & 2 & $167 \cdot 34$ \\
10 & 6 & $85 \cdot 83(2 \cdot 05)$ & 3 & $257 \cdot 49$ \\
20 & 7 & $95 \cdot 97(0 \cdot 38)$ & 3 & $287 \cdot 91$ \\
50 & 8 & $97 \cdot 42(0 \cdot 34)$ & 4 & $389 \cdot 68$ \\
100 & 10 & 100 & 5 & $500 \cdot 0$ \\
\hline
\end{tabular}

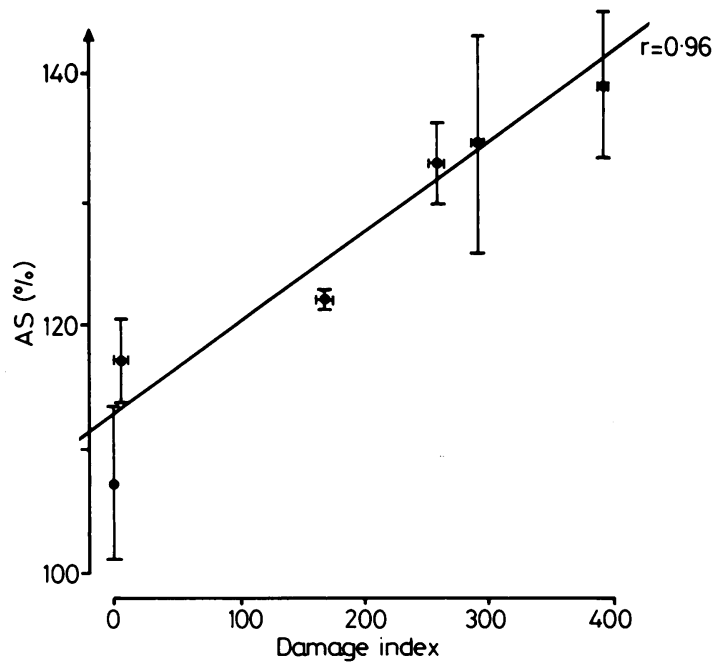

Fig. 5 Correlation of alkaline secretion (AS given as per cent increase above baseline levels) and mucosal damage (given as damage index) after luminal exposure to different concentrations of $\mathrm{HCl}: 0 \cdot 1 \mathrm{mmol}(n=4), 1 \mathrm{mmol}(n=6)$, $5 \mathrm{mmol}(n=6), 10 \mathrm{mmol}(n=6), 20 \mathrm{mmol}(n=7), 50 \mathrm{mmol}$ $(n=8)$ for 10 minutes. $y=111 \cdot 4 \times+0.074(p<0.001$, Kendall's Tau correlation coefficient). 
mechanism to respond to luminal acid may not be operative in our preparation.

It was also shown that the stimulation of alkaline secretion is not specific for acid and occurs also after luminal ethanol exposure. As ethanol was a very hypertonic solution we can assume that its effect as a damaging agent and stimulant of alkaline secretion was unspecific and might be produced by other hypertonic solutions, too. Increased alkaline secretion after mucosal damage was described previously by Svanes ${ }^{15}$ who treated bullfrog gastric mucosa with $\mathrm{NaCl}, 1 \mathrm{M}$. Shortly after damage luminal alkalinisation occurred, much higher than usually measured in this tissue. Further experiments revealed that this was mainly passive diffusion of $\mathrm{HCO}_{3}-$. Acid stimulated alkaline secretion in the rabbit duodenum is also a passive phenomenon. The amount of inhibition induced by ouabain or anoxia was unchanged after any of the acid concentrations used in this study. Therefore most of the increase in alkaline secretion after acid exposure occurred by passive diffusion that was only abolished by removal of $\mathrm{HCO}_{3}-$ from the nutrient bath. An increase in passive permeability in response to luminal acid exposure was recently reported by Wilkes and Garner ${ }^{8}$ in experiments on the rat using $10 \mathrm{mmol} / \mathrm{l}$ acid. The increase of mucosal permeability in these experiments was demonstrated with markers such as inulin and radiolabelled urea. This increase was not seen after topical application of prostaglandin $E_{2}$. Although most of the authors reporting acid stimulated alkaline secretion in the duodenum did not carry out histology on their tissues to exclude mucosal damage, there seem to exist two responses to luminal acid: either an active prostaglandin mediated $\mathrm{HCO}_{3}$ - transport for protection of the intact mucosa, or a passive transmucosal flow of $\mathrm{HCO}_{3}-$ protecting the repair process in the duodenum. These are necessary mechanisms and their predominance is dependent on the acid tolerance of the duodenal mucosa in different species.

Part of this work have previously been published in abstract form (Gastroenterology 1986; 90: 1678).

\section{References}

1 Flemström G, Garner A, Nylander O, Hurst BC, Heylings JR. Surface epithelial $\mathrm{HCO}_{3}-$ transport by mammalian duodenum in vivo. Am J Physiol 1982; 243: G348-58.

2 Simson JNL, Merhav A, Silen W. Alkaline secretion by amphibian duodenum. I. General characteristics. Am J Physiol 1981; 240: G401-8.

3 Flemström G, Heylings JR, Garner A. Gastric and duodenal $\mathrm{HCO}_{3}-$ transport in vitro: effects of hormones and local transmitters. Am J Physiol 1982; 242: G100-10.

4 Flemström G, Garner A. Gastroduodenal $\mathrm{HCO}_{3}-$ transport: characteristics and proposed role in acidity regulation and mucosal protection. Am J Physiol 1982; 242: G183-93.

5 Heylings JR, Garner A. Influence of luminal acidification on bicarbonate transport by gastric and duodenal isolated mucosae. Prostaglandins 1981; 21: suppl: 67-71.

6 Heylings JR, Garner A, Flemström G. Regulation of gastroduodenal $\mathrm{HCO}_{3}-$ transport by luminal acid in the frog in vitro. Am J Physiol 1984; 246: G235-42.

7 Garner A, Hurst BC, Heylings JR, Flemström G. Role of gastroduodenal $\mathrm{HCO}_{3}$ - transport in acid disposal and mucosal protection. In: Case RM, Garner A, Turnberg LA, Young JA, eds. Electrolyte and water transport across gastrointestinal epithelia. New York: Raven Press, 1982: 235-52.

8 Wilkes JM, Garner A, Peters TJ. Duodenal epithelial permeability in relation to stimulation of alkaline secretion [Abstract]. Gut 1986; 27: A604.

9 Konturek SJ, Bilski J, Tasler J, Laskiewicz J. Gastroduodenal alkaline response to acid and taurochlorate in conscious dogs. Am J Physiol 1984; 247: G149-54.

10 Isenberg JI, Smedfors B, Johansson C. Effect of graded doses of intraluminal $\mathrm{H}^{+}$, prostaglandin $\mathrm{E}_{2}$ and inhibition of endogenous prostaglandin synthesis on proximal duodenal bicarbonate secretion in unanaesthetized rats. Gastroenterology 1984; 88: 303-7.

11 Isenberg JI, Hogan DL, Koss MA, Selling JA. Human duodenal mucosal bicarbonate secretion. Evidence for basal secretion and stimulation by hydrochloric acid and a synthetic prostaglandin $\mathrm{E}_{1}$, analogue. Gastroenterology 1986; 91: 370-8.

12 Wenzl E, Feil W, Starlinger M, Schiessel R. Alkaline secretion: a protective mechanism against acid injury in rabbit duodenum. Gastroenterology 1987; 92: 709-15.

13 Sjöstrand SE, Rydberg B, Olbe L. Analysis of the action of cimetidine and metiamide on gastric acid secretion in the isolated guinea pig mucosa. Naunyn Schmiedebergs Arch Pharmacol 1977; 296: 139-42.

14 Smith PL, Cascairo MA, Sullivan SK. Sodium dependence of luminal alkalinization by rabbit ileal mucosa. Am J Physiol 1985; 249: G358-68.

15 Svanes K, Ito S, Takeuchi K, Silen W. Restitution of the surface epithelium of the in vitro frog gastric mucosa after damage with hyperosmolar sodium chloride. Morphologic and physiologic characteristics. Gastroenterology 1982; 82: 1409-26. 